\title{
Vapor-induced Crystallization in Alcoholic Sorption using Poly(lactic acid) Films
}

\author{
Y. Moriizumi \& K. Nagai ${ }^{*}$ \\ Department of Applied Chemistry, Meiji University, Kawasaki, Japan \\ Submitted: 25/5/2018. Revised edition: 9/7/2018. Accepted: 11/7/2018. Available online: $21 / 11 / 2018$
}

\begin{abstract}
In this study, the sorption amount of alcohols (ethanol, 1-propanol, and 2-propanol) vapors on poly(lactic acid) (PLA) membrane was measured resulting in high increase in sorption. Sorption amount increases as the molecular volume of vapor decreases in the low-pressure region. The sorption amount of branched 2-propanol is lower than that of linear 1-propanol. In the high-pressure region, the PLA film tends to swell or plasticize as the cluster size increases, thereby increasing sorption. In addition, the alcohol vapor sorbed in the PLA film causes vaporinduced crystallization, which is in contrast to solvent- and thermally-induced crystallization, and forms an unknown crystal structure.
\end{abstract}

Keywords: Poly(lactic acid), membrane, crystallization, X-ray, biodegradable

\subsection{INTRODUCTION}

Although various plastic products enrich our lives, they adversely affect the environment. One of the most severe environmental issues is marine pollution, which is due to increased marine waste flowing into the ocean and the coast. Light materials such as plastic products, mostly beverage bottles and microplastics derived from plastic decomposition, account for $30 \%$ (i.e., 4.8-12.7 million tons) of wastes flowing into the sea $[1,2]$. The accumulation of these wastes leads to entanglement of marine organisms in a drifting plastic product, their tearing, and death as well as collapse of the ecosystem balance [3-5]. Given their light weight, microplastics can easily drift off the ocean and may be inadvertently swallowed by marine organisms [4]. Hence, plastic wastes drifting in the ocean must be reduced. Under such situation, biodegradable plastics have received attention as a substitute to conventional plastics.
Biodegradable can be decomposed into carbon dioxide and water by microorganisms in the ground or sea [6, 7]. Thus, the use of biodegradable plastics can reduce the amount of marine wastes and suppress their adverse effects on the ecosystem.

Poly(lactic acid) (PLA) is a biodegradable plastic recently considered as substitute for conventional plastic in the production of beverage bottles. PLA is derived from plants, such as corn, and has attracted attention as an environmentfriendly material because of its carbonneutral nature [6-8]. In addition, PLA exhibits excellent molding processability because of its high transparency and low glass transition temperature $\left(T_{g}\right)$ of $60{ }^{\circ} \mathrm{C}$. Thus, it can be a potential material for beverage bottles [9-11].

Many beverages contain highly polar perfume ingredients, such as alcohols and esters. Dissolution of these ingredients and their subsequent interaction with PLA cause swelling 
and plasticization, leading to the degradation of the bottle material $[8$, 12]. Furthermore, PLA crystallization occurs due to solvent-induced crystallization caused by the dissolution of an organic solvent with high polarity in the polymer chain interstitial spaces of PLA [13, 14]. This process causes cloudiness for PLA, which complicates confirmation of the content in bottle containers, where high transparency is important $[13,14]$.

To elucidate the material degradation mechanism of perfume ingredients, scholars must investigate the solubility of the ingredients on PLA. In general, the dissolution of gas and vapor molecules with respect to macromolecules is explained by the physical phenomenon sorption, which summarizes adsorption onto the membrane surface and absorption inside the membrane [15]. Sorption amount indicates the amount of gaseous molecules dissolved in the polymer. Therefore, understanding the sorption property of perfume ingredients on the PLA membrane is important in the application of PLA to bottle containers in the future.

PLA has five types of crystal structures: $\alpha, \beta, \gamma, \alpha^{\prime}$, and $\alpha^{\prime \prime}$ [16-26]. Figure 1 shows the four kinds of crystal structures [27]. $\alpha$ - and $\beta$-type crystal structures are formed by solventinduced crystallization with alcohol or ester $[13,14]$. To date changes in the crystal structure have not been reported in crystallization induced by organic vapor $[13,14]$.

Considering that alcohol is one of the perfume ingredients in beverage, alcohol vapor with ethyl, propyl and isopropyl groups as substituents were used in this study. Alcohol vapor sorption measurement on the amorphous PLA membrane was then conducted. The physicochemical properties of PLA membranes after vapor sorption were characterized using proton nuclear magnetic resonance $\left({ }^{1} \mathrm{H}\right.$ NMR) spectroscopy, attenuated total reflectance (ATR) Fourier transform infrared (FTIR) spectroscopy, polarized optical microscopy (POM), contact angle, differential scanning calorimeter (DSC), ultraviolet-visible (UV-vis) spectroscopy, and wide-angle X-ray diffraction (WAXD). Basing form measurement results, the influence of the different structures of the alkyl group of alcohol vapor on higher order structures of PLA membrane was compared with those of water vapor. Experimental results of water vapor were obtained from previous reports [12]. DSC and UV-vis measurement data were derived through experiment and supplemented with data [12].

\subsection{METHODS/THEORY}

\subsection{Preparation of Membranes}

In this study, PLA membranes were prepared as previously described [28]. The PLA polymer had a 4032D product (NatureWorks LLC, Minnetonka, USA). Lactic acid exists as two isomers, (L- and D- lactic acid), and the isomer ratio (L:D) of the PLA used in this study ranged from 96.0:4.0 to 96.8:3.2 [28]. PLA membranes were prepared by casting $2 \mathrm{wt} \%$ dichloromethane solution of each solvent onto a flatbottomed Petri dish in a glass bell-type vessel, which was dried under atmospheric pressure at room temperature. Each solvent was allowed to evaporate for 48 hours. The dried PLA membranes were thermally treated under vacuum for 48 hours at $70{ }^{\circ} \mathrm{C}$ to completely eliminate the residual solvent and obtain amorphous PLA membranes. The thermally-treated PLA membranes were cooled at room temperature under atmospheric pressure. ${ }^{1} \mathrm{H}-\mathrm{NMR}$ (JNM-ECA500, JEOL Ltd., Tokyo, Japan) analysis was 


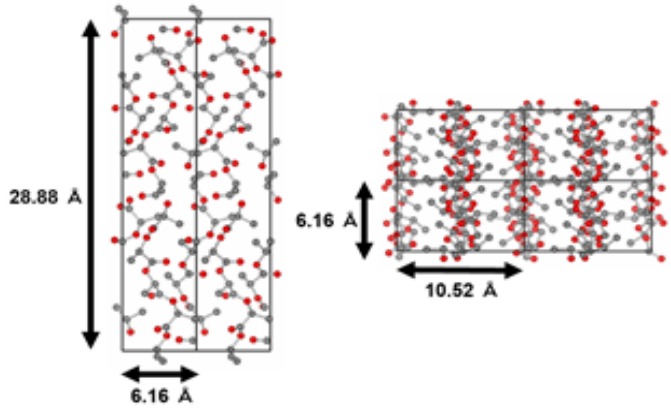

(a) $\alpha$-crystal structure

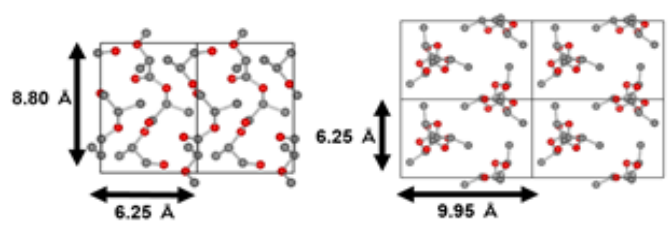

(c) $\gamma$-crystal structure

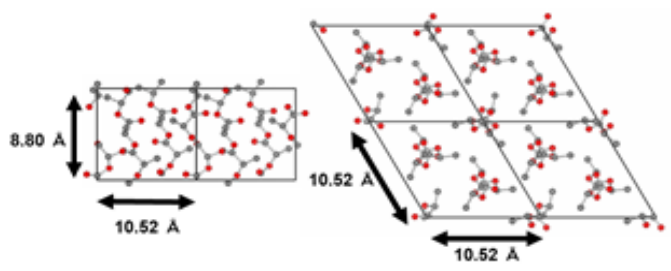

(b) $\beta$-crystal structure

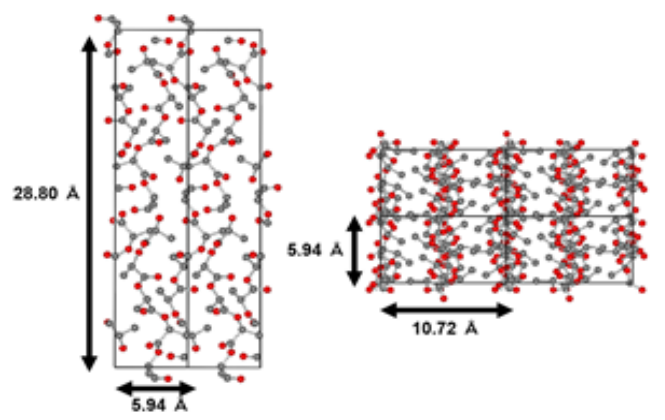

(d) $\alpha$ '-crystal structure

Figure 1 Calculated model of (a) $\alpha$-crystal, (b) $\beta$-crystal, (c) $\gamma$-crystal, and (d) $\alpha^{\prime}$-crystal PLA structures

used to confirm the removal of the residual solvent. Membrane thickness varied from $35 \mu \mathrm{m}$ to $45 \mu \mathrm{m}$, and the uncertainty of each membrane thickness was $\pm 1 \mu \mathrm{m}$.

\subsection{Measurement of Alcohol and Water Vapor Sorption}

Sorption data were determined during the membrane state for at least three samples to confirm the reproducibility of the experimental results. Alcohol vapor sorption in PLA membranes was determined gravimetrically as a function of pressure at $35^{\circ} \mathrm{C} \pm 1^{\circ} \mathrm{C}$ by using a calibrated helical quartz spring sorption system. The sorption system was evacuated for 12 hours similar to the measurement temperature after the sample was introduced into the chamber to degas the PLA membrane [29]. Ethanol (Junsei Chemical, Tokyo, Japan), 1-propanol (Junsei Chemical,
Tokyo, Japan), and 2-propanol (Junsei Chemical, Tokyo, Japan) from which dissolved gas was removed by freezedrying were used as each vapor. Alcohol vapor was introduced into the chamber at a fixed pressure. The resulting change in spring extension was monitored with differential transformer transducers and recorded up to $9.0 \mathrm{cmHg}$ in ethanol, $3.6 \mathrm{cmHg}$ in 1-propanol, and $7.2 \mathrm{cmHg}$ in 2propanol as a function of time. The saturated vapor pressure $\left(p / p_{\text {sat }}\right)$ values were $10.32 \mathrm{cmHg}$ in ethanol, 3.91 $\mathrm{cmHg}$ in 1-propanol, and $8.10 \mathrm{cmHg}$ in 2-propanol [30]. Experiments were performed in the order of increasing relative pressure $\left(p / p_{\text {sat }}\right)$ with a specific interval. $p / p_{\text {sat }}$ was provided stepwise into the chamber from 0 to 0.9 . The equilibrium concentration of each vapor sorption was calculated as follows: 


$$
C=22414 \times \frac{m_{s} \rho_{p}}{m_{p} M W_{s}}
$$

where $C$ is the concentration of each vapor sorption $\left[\mathrm{cm}^{3}(\mathrm{STP}) / \mathrm{cm}^{3}\right.$ (polymer) $], m_{p}$ is the polymer mass $(\mathrm{g}), m_{s}$ is the penetrant mass in the polymer $(\mathrm{g}), \rho_{p}$ is the polymer density $\left(\mathrm{g} / \mathrm{cm}^{3}\right), M W_{s}$ is the penetrant molecular weight $(\mathrm{g} / \mathrm{mol})$, and 22414 is a conversion factor $\left(\mathrm{cm}^{3}(\mathrm{STP}) / \mathrm{mol}\right)$. The solubility coefficient of each vapor in the polymer membrane is expressed by Equation (2), as follows:

$$
S=\frac{C}{p}
$$

where $S$ is the solubility coefficient $\left[\mathrm{cm}^{3}(\mathrm{STP}) /\left(\mathrm{cm}^{3}\right.\right.$ (polymer) $\left.\left.\mathrm{cmHg}\right)\right], C$ is the concentration of each vapor sorption $\left[\mathrm{cm}^{3}(\mathrm{STP}) / \mathrm{cm}^{3}\right.$ (polymer)], and $P$ is the equilibrium pressure $(\mathrm{cmHg})$.

Clusters of each vapor molecules are formed by self-hydrogen bonds between carbonyl or hydroxyl groups. We investigated the clustering of each vapor molecule. Clustering in polymer membranes is expressed using the Zimm and Lundberg formula [31, 32]:

$$
\frac{G_{11}}{V_{1}}=-\phi_{2}\left[\frac{\partial\left(a_{1} / \phi_{1}\right)}{\partial a_{1}}\right]_{p, T}-1
$$

where $G_{11}$ represents the cluster integral; $V_{1}$ is the partial molar volume of the penetrant molecule; $\phi_{1}$ and $\phi_{2}$ are the volume fractions of the penetrant molecule and the polymer, respectively; and $a_{1}$ is the activity of alcohol and water molecules. At a given activity, $a_{1}$ is determined from the equilibrium sorption isotherm using the following equation:

$$
\phi_{1}=\frac{v R_{w}}{1+v R_{w}^{\prime}}
$$

where $v$ is the ratio of polymer density and alcohol and water molecule, and $R$ $(\mathrm{g} / \mathrm{g}[$ polymer $])$ is the equilibrium sorption regain. Clustering functions have values of -1 for pure, condensed systems. In a pure system, a molecule excludes another molecule from its own molecular volume but has no other effect on the system.

\subsection{Characterization}

For the PLA membrane used for physical property measurement after alcohol vapor sorption, samples were produced using the same equipment as the sorption amount measurement. Vapor was introduced for up to the maximum pressure at $35{ }^{\circ} \mathrm{C}$ and held for more than 1 hour in a state where the sorption amount reached the equilibrium. Then vapor was vacuum dried for 12 hours or more for the experiment. The PLA membrane after water vapor sorption was subjected to DSC measurement and UV-vis spectroscopy in the same manner as the other samples.

${ }^{1} \mathrm{H}-\mathrm{NMR}$ spectra were obtained with a JNM-ECA500 (LEOL Ltd., Tokyo, Japan) at $25{ }^{\circ} \mathrm{C}$. The solvent used was deuterated chloroform $\left(\mathrm{CDCl}_{3}\right)$. ATR-FTIR spectra were obtained with ATR-PRO450-S (JASCO Co., Tokyo, Japan) using the HATR ZnSe $45^{\circ}$ flat plate (PIKE Technologies, Watertown, USA). The incidence angle was set at $45^{\circ}$, the resolution was $2 \mathrm{~cm}^{-1}$, the cumulated number was 32 times, the measurement temperature was $23{ }^{\circ} \mathrm{C} \pm 1{ }^{\circ} \mathrm{C}$, and the relative humidity was $50 \% \pm 5 \% \mathrm{RH}$.

Orthoscope observation was performed using an Olympus BX-51 Polarization microscope (POM) (Olympus Inc., Tokyo Japan) under cross Nicol condition. Polarization images were observed under an additive color at $530 \mathrm{~nm}$ with a sensitive color plate.

Membrane density was measured by flotation method at $23^{\circ} \mathrm{C} \pm 1^{\circ} \mathrm{C}$. The membrane was added with a calcium nitrate tetrahydrate (Junsei Chemical, Tokyo, Japan) when it sunk in the solution and pure water added when it 
floated in the solution. This operation was continued until the membrane did not float and sink in the solution.

Contact angle was measured by contact angle meter IMC-159D (Imoto Machinery Co., Ltd., Kyoto, Japan). Ultrapure water droplets were dropped on the membranes using a microsyringe and fixed on the apparatus at $23{ }^{\circ} \mathrm{C} \pm$ $1{ }^{\circ} \mathrm{C}$. Images were captured within 5 seconds after dropping the water droplet, and the contact angle was calculated from the three-point measurement.

Thermal analysis data were obtained using a diamond differential scanning calorimeter (Perkin-Elmer, Inc., Shelton, USA). The sample-pankit alum (Perkin-Elmer, Inc., Shelton, USA) was aluminium. Given that these data are used to discuss crystalline structure and crystallinity $\left(X_{C-D S C}\right)$, the first heating scan data (i.e., before annealing) represent the optimum condition relative to the second heating scan data. Heat scan was performed from $20{ }^{\circ} \mathrm{C}$ to $200{ }^{\circ} \mathrm{C}$ at a heating rate of $10^{\circ} \mathrm{C} / \mathrm{min}$ in nitrogen atmosphere. $T_{g}$ was determined as the middle point of endothermic transition. The crystallization temperature $\left(T_{c}\right)$ and melting temperature $\left(T_{m}\right)$ were determined as the maximum value of each peak. $X_{C-D S C}$ was estimated using Equation (5) [33, 34]:

$X_{C-D S C}=\frac{\Delta H_{m}+\Delta H_{c}}{\Delta H_{m}^{0}} \times 100$

where $\Delta H_{m}$ and $\Delta H_{c}$ are melting and crystallization enthalpies of a polymer $(\mathrm{J} / \mathrm{g})$, respectively; and $\Delta H^{0}{ }_{m}$ is the enthalpy of the PLA (L-donor $100 \%$ ) crystal with infinite crystal thickness and has a value of $93 \mathrm{~J} / \mathrm{g}$ [35].

UV-vis spectra were obtained on a UV-3100 spectrophotometer (Shimadzu Co., Kyoto, Japan) at $23{ }^{\circ} \mathrm{C}$ $\pm 1{ }^{\circ} \mathrm{C}$ within the wavelength range of 200-800 nm.
WAXD measurement was performed using a RINT 2200 Ultima-III X-Ray diffractometer (Rigaku, Corp., Tokyo, Japan) with a $\mathrm{Cu}-\mathrm{K} \alpha$ radiation source at $40 \mathrm{kV}$ and $20 \mathrm{~mA}$ in a dispersion angle ranging from $5.00^{\circ}$ to $30.00^{\circ}$ and a scanning speed of $2 \% \mathrm{~min}$ at $23{ }^{\circ} \mathrm{C} \pm$ $1{ }^{\circ} \mathrm{C}$. $d$-spacing was calculated according to Bragg's conditions (6) and represents the mean distance between polymer chains:

$\lambda=2 d \sin \theta$

where $\lambda$ is the $\mathrm{X}$-ray wavelength $(1.54$ $\AA$ ), and $d$ is the distance of lattice spacing $(\AA)$. Moreover, the value of $\theta$ was obtained from the diffraction angle at peak maximum intensity determined from the Gauss function.

All characterization data were determined in at least three membrane samples to confirm the reproducibility of the experimental results.

\subsection{RESULTS AND DISCUSSIONS}

\subsection{Alcohol and Water Vapor Sorption}

Figure 2 shows all relative pressure values determined. The sorption amount immediately increased after introducing vapor with time and gradually reached the equilibrium. In general, when organic vapor is sorbed in a glassy polymer, Fickian diffusion and structural relaxation of the polymer chain simultaneously occur [36]. Given that Fickian diffusion occurs within a short time and structural relaxation of the polymer chain occurs over a long period of time, the sorption amount increases, then decreases and finally reaches the equilibrium in some cases [36]. In the present study, the sorption amount did not increase before it reached the equilibrium because of the fast structural relaxation speed of the polymer chain generated from alcohol vapor-induced PLA crystallization. 


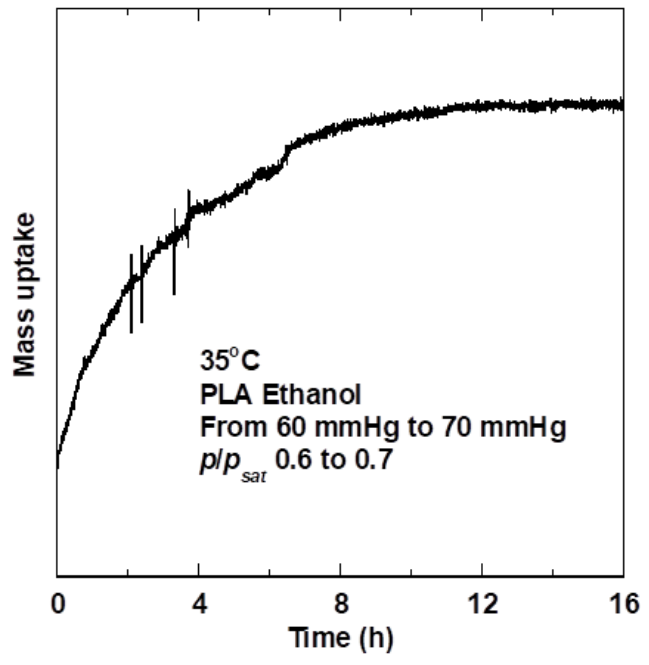

Figure 2 Ethanol sorption kinetics in the PLA membrane at $35{ }^{\circ} \mathrm{C}$. The vapor pressure ranged from $60 \mathrm{mmHg}$ to 70 $\mathrm{mmHg}$

Moreover, the time taken for relaxation of the polymer chain was assumed to be shorter than the time taken for the sorption amount to reach the equilibrium.

Figure 3(a) shows the sorption isotherms for ethanol, 1-propanol, and 2-propanol vapor on PLA membranes at $35{ }^{\circ} \mathrm{C}$. For comparison, the water vapor data previously obtained are also plotted [12]. The vertical axis represents the vapor sorption amount $C$, and the horizontal axis represents the introduction pressure. Until the pressure of $2.0 \mathrm{cmHg}$, the sorption amounts for all vapors were almost the same. However, after approximately $5.0 \mathrm{cmHg}$ in ethanol, $2.0 \mathrm{cmHg}$ in 1propanol, and $4.0 \mathrm{cmHg}$ in 2-propanol, the sorption amount of each vapor substantially increased, which resulted in swelling and plasticization. Meanwhile, for water vapor, no rapid increase in the sorption amount of alcohol was observed. These results indicate that alcohol shows stronger interaction with PLA compared with water.

Figure 3(b) shows the sorption isotherms for ethanol, 1-propanol, and 2-propanol vapors on the PLA membranes at $35{ }^{\circ} \mathrm{C}$. For comparison, the water vapor data previously obtained are also plotted [12]. The vertical axis represents the vapor sorption amount $C$, and the horizontal axis represents the relative introduction pressure when the saturated vapor pressure of each vapor is $p / p_{\text {sat }}=1.0$. The sorption amount was in the order of ethanol $>1$-propanol $>2$-propanol $>$ water vapor until $p / p_{\text {sat }}=0.6$. The sorption amount of 1-propanol and 2propanol sharply increased at approximately 0.6 relative pressure, and the sorption amount at the relative pressure of 0.9 was high in the order of 1-propanol $>$ 2-propanol $>$ ethanol $>$ water vapor. In previous studies, the sorption amount (swelling rate) when impregnated in liquid alcohol was in the order of 2-propanol > 1-propanol > ethanol [13]. This trend was consistent with the magnitude of the rate of increase in sorption amount after the relative pressure of 0.6 . Meanwhile, the sorption amount of water vapor at a relative pressure of 0.9 was lower than the sorption amount when impregnated in a liquid state. The increased rate of the sorption amount after a relative pressure of 0.6 depended on the molecular volume of each molecule. The larger the molecular volume is, the more easily the swelling and plasticization of the PLA membrane is likely to occur, and the larger the sorption amount is.

Figure 4 shows the solubility curves of ethanol, 1-propanol, and 2-propanol vapors for the PLA membrane calculated from Equation (2) on the basis of Figure 3 (b). For comparison, the water vapor data previously obtained are also plotted [12]. The vertical axis represents solubility coefficient, $S$ calculated from the sorption amount, and the horizontal axis represents the relative introduction pressure with the saturated vapor pressure of each vapor set to $p / p_{\text {sat }}=1.0$. 

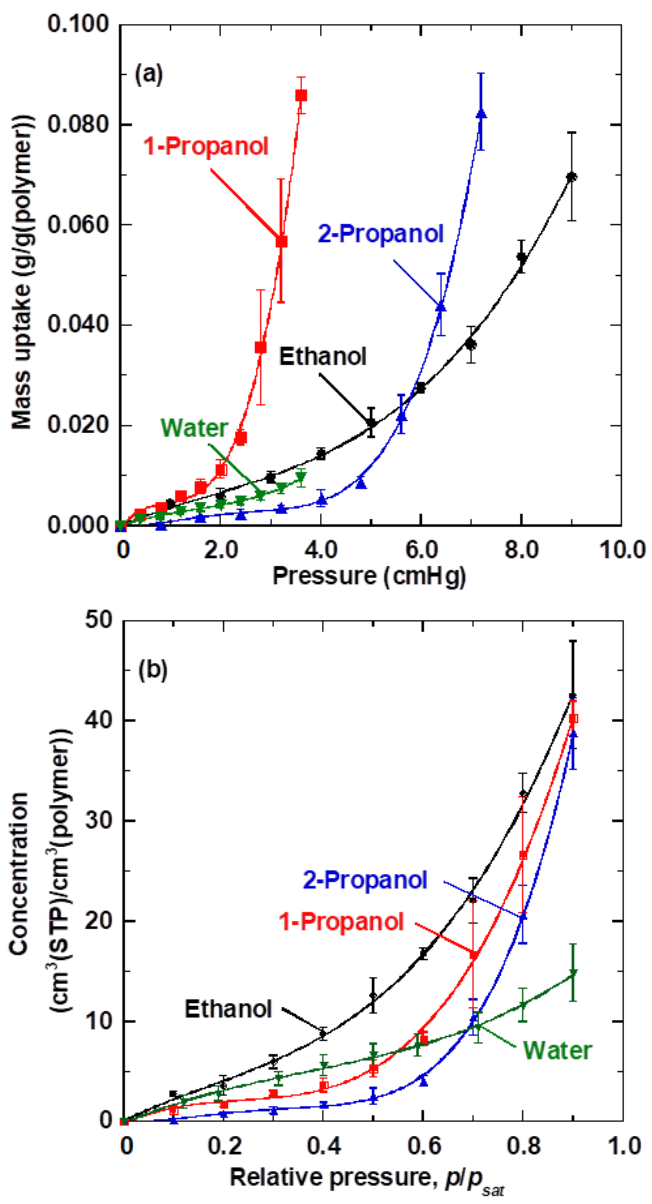

Figure 3 (a) Mass uptake and (b) sorption isotherms of ethanol $(\bullet), 1$ propanol (๘), 2-propanol ( $\mathbf{\Delta})$, and water $(\boldsymbol{\nabla})$ [12] vapors in PLA membranes

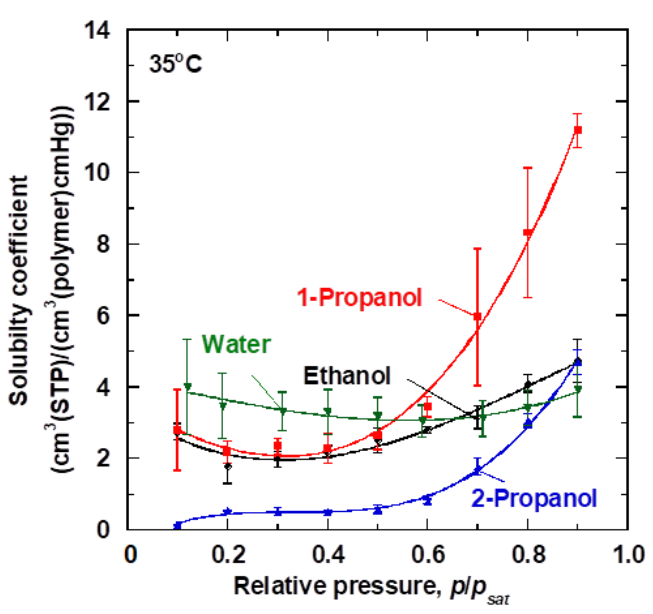

Figure 4 Solubility coefficients for

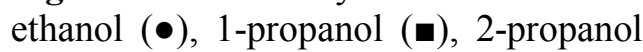
$(\boldsymbol{\Delta})$, and water $(\boldsymbol{\nabla})[12]$ vapors in PLA membranes
For ethanol and 1-propanol, the solubility coefficient increased at the relative pressure of approximately 0.3 . Water vapor increased the solubility coefficient at the relative pressure of approximately 0.6 . The solubility coefficient in the low-pressure region was in the order of 2-propanol $<$ ethanol $=1$-propanol $<$ water. The solubility coefficient at a relative pressure of 0.9 increased in the order of water $<$ ethanol $\leqq 2$-propanol $<1$-propanol. Regarding the adsorption of vapor on the membrane surface and dissolution in the unrelaxed volume in the lowpressure region, steric hindrance due to the presence or absence of the side chain considerably influences the solubility coefficient without depending on the length of the main chain of the alkyl group. Here, the solubility parameters of PLA, ethanol, 1-propanol, 2-propanol, and water are 21.2, 29.7, 24.5, 23.5, and 47.9 $\mathrm{MPa}^{1 / 2}$, respectively [13, 37]. In general, the solubility dissolves as the solubility parameter of a polymer approaches the value of a solvent. The solubility parameter value of 2-propanol vapor was the closet to that of PLA, followed by 1-propanol, ethanol and water, but the final solubility coefficient values showed a different order from this one. Hansen's solubility parameter is determined by three factors, such as dispersive power, dipole force, and hydrogen bonding force. Among these three factors, the parameters of the dispersion powers of PLA, ethanol, 1propanol, 2-propanol, and water were $17.5,15.8,16.0,15.8$, and $15.5 \mathrm{MPa}^{1 / 2}$, respectively $[13,37]$. The solubility in PLA was suggested to be largely influenced by the dispersive power, because the difference in the dispersion power parameter with PLA increased in the order of 1-propanol $<2$-propanol $=$ ethanol $<$ water. Dispersive force, which is the intermolecular force due to dipole occurring instantaneously, 
worked larger than two parameters as the distance became shorter. Dispersive power had a huge influence because the distance between PLA and each vapor was becoming close when the vapor dissolute was present in the membrane.

Figure 5 shows the relationship between $\phi_{1} G_{11} / V_{1}$ and relative pressure calculated from the sorption isotherms of ethanol, 1-propanol, and 2-propanol of the PLA membrane. For comparison, the water vapor data previously obtained are also plotted [12]. The vertical axis shows the cluster function, $\phi_{1} G_{11} / V_{1}$ calculated from the sorption isotherm, and the horizontal axis shows the relative introduction pressure with the saturated vapor pressure of each vapor being $p / p_{\text {sat }}=1.0$. In all experimental conditions, $\phi_{1} G_{11} / V_{1}$ showed a negative value in the lowpressure region, but increased with increasing relative pressure and showed a positive value in the high-pressure region. For the three alcohol types, the waveform showed that the value of the cluster function reached the steady as the relative pressure reached 0.9 . In addition, the size of the final cluster increased in the order of water $<$ ethanol $<1$-propanol $<2$-propanol vapor. Here, the critical volumes of water, ethanol, 1-propanol, and 2-propanol, which are indicators of vapor cohesiveness, are 55 , 116, 219, and $222 \mathrm{~cm}^{3} / \mathrm{mol}$, respectively [30]. These results indicate that the cluster size depends on the cohesive force.

Table 1 shows the cluster initiation relative pressure of ethanol, 1-propanol, and 2-propanol in the PLA membrane and the number of molecules at the maximum cluster formation. For comparison, the water vapor data previously obtained are also plotted [12]. Three alcohols formed clusters at a relative pressure of approximately 0.3 , but water vapor showed that clusters formed at a relative pressure of approximately 0.5 . The number of

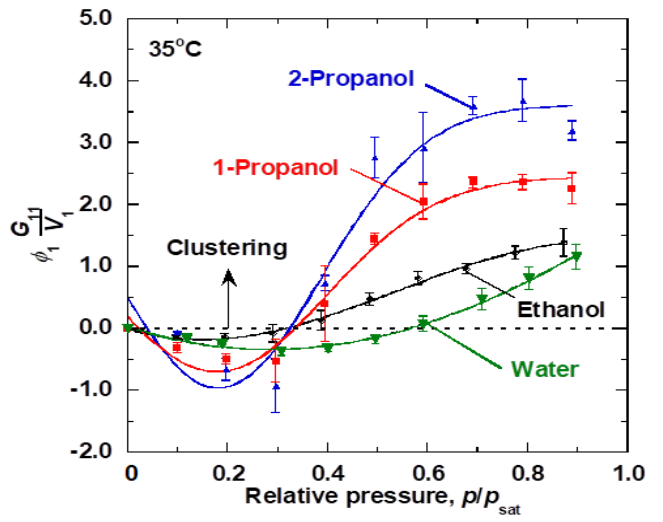

Figure 5 Cluster formation of ethanol $(\bullet)$, 1-propanol (घ), 2-propanol ( $\boldsymbol{\Delta})$, and water $(\boldsymbol{\nabla})$ [12] vapors in PLA membranes

molecules at the time of maximum cluster formation increased in the order of water $<$ ethanol $<1$-propanol $<2$ propanol. The hydrogen-bonding force working in cluster formation between alcohol and water, more clusters formed as the difference in hydrogen-bonding strength of the solubility parameter with PLA decreased in the low relative pressure. These findings suggest that the sorption amount in the highpressure region increases with the number of molecules at the time of maximum cluster formation.

\subsection{Characterization}

Figure 6 shows the ${ }^{1} \mathrm{H}-\mathrm{NMR}$ spectra of the PLA membrane before and after sorption amounts for ethanol, 1propanol, and 2-propanol vapors. The vertical axis shows the spectral intensity, and the horizontal axis shows chemical shift. The analysis results are as follows: PLA: ${ }^{1} \mathrm{H}-\mathrm{NMR}(500 \mathrm{MHz}$, $\left.\mathrm{CDCl}_{3} \delta\right) ; 5.15-5.17\left(\mathrm{H}, \mathrm{H}_{1}\right), 1.56-1.57$ ppm $\left(3 \mathrm{H}, \mathrm{H}_{2}\right)$. No clear change in the ${ }^{1} \mathrm{H}-\mathrm{NMR}$ spectrum was observed before and after sorption amount measurement. The results showed that the sorption of alcohol did not affect the chemical structure. 
Table 1 Parameters of clustering ethanol, 1-propanol, 2-propanol and water vapor in PLA membranes

\begin{tabular}{ccc}
\hline $\begin{array}{c}\text { Vapor sorption } \\
\text { components }\end{array}$ & Clustering point & $\begin{array}{c}\text { Mean cluster size } \\
\left(\boldsymbol{p} / \boldsymbol{p}_{\text {sat }} \boldsymbol{> 0 . 6}\right)\end{array}$ \\
\hline Ethanol & $0.31 \pm 0.05$ & $2.39 \pm 0.22$ \\
1-Propanol & $0.34 \pm 0.02$ & $3.71 \pm 0.21$ \\
2-Propanol & $0.32 \pm 0.02$ & $4.68 \pm 0.34$ \\
Water $^{(\mathrm{a})}$ & $0.54 \pm 0.08$ & $2.03 \pm 0.28$ \\
\hline
\end{tabular}

(a) Data from Reference [12]

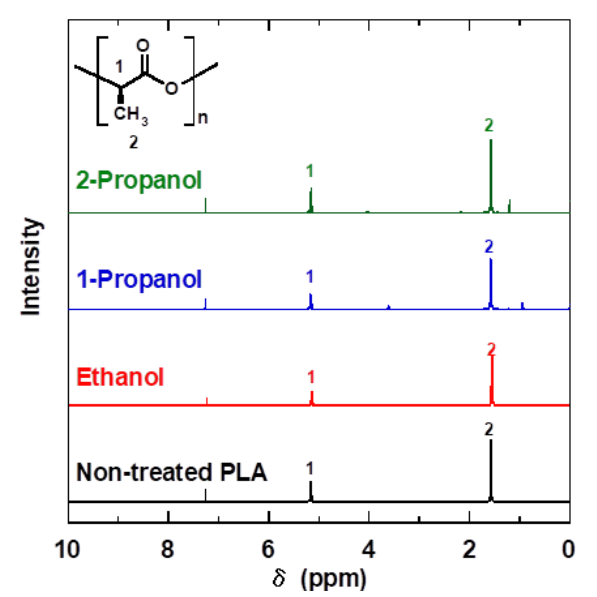

Figure $6{ }^{1} \mathrm{H}-\mathrm{NMR}$ spectra of PLA membranes before [28] and after sorption measurements in ethanol, 1propanol, and 2-propanol vapors.

Figure 7 (a) shows the ATR-FTIR spectra of the PLA membrane before and after the measurement of ethanol, 1-propanol, and 2-propanol vapor sorption amount [28]. The vertical axis shows the spectral intensity, and the horizontal axis shows the wave number $\left(\mathrm{cm}^{-1}\right)$. The analysis results are as follows: PLA: FT-IR (ATR); 29952998, 2945-2948 (C-H stretching), 1754-1761 (C=O stretching), 14531457 (C-H stretching, $\mathrm{C}-\mathrm{H}$ bending), 1179-1188, 1092-1097 cm $\mathrm{cm}^{-1}$ (C-O-C bending). No clear change in ATRFTIR spectrum was observed before and after sorption amount measurement. Alcohol vapor sorption did not affect the chemical structure. The ${ }^{1} \mathrm{H}-\mathrm{NMR}$ and ATR-FTIR spectra showed that no chemical reaction clearly occurred between alcohol and PLA; thus, only its physical change can be discussed at this point.

Figure 7 (b) shows the ATR-FTIR spectra at $980-880 \mathrm{~cm}^{-1}$ before and after the sorption of ethanol, 1-propanol, and 2-propanol vapors [28]. Figure 7 (c) shows the PLA membrane ATR-FTIR difference spectra after the sorption of ethanol, 1-propanol, and 2-propanol vapors on the basis of the PLA membrane before sorption. The $\alpha-, \beta$-, and $\alpha$-type crystal structures of PLA showed peaks at 921,912 , and $924 \mathrm{~cm}^{-}$ 1 , respectively [16-26]. As shown in Figure 7 (b) and Figure 7 (c), the PLA membranes after the sorption of ethanol and 1-propanol vapors had $\alpha$ - and $\beta$ type crystal structures, respectively, whereas the PLA membrane after the sorption of 2-propanol vapor had $\alpha$-type crystal structure.

Figure 8 shows the appearance photographs and POM images of the PLA film before and after the sorption of ethanol, 1-propanol, 2-propanol, and water vapors and the thermally-induced and solvent-induced crystallized PLA film. Data after water vapor sorption and thermally- and solvent-induced crystallization were cited from previous studies $[12,13,28]$. On the other hand, both non-treated PLA film and the PLA film after measuring the water vapor sorption were colorless and transparent, and no spherulites were observed from the POM image. On the other hand, appearance photographs after measuring alcohol vapor sorption opaque. In addition, small spherulites 

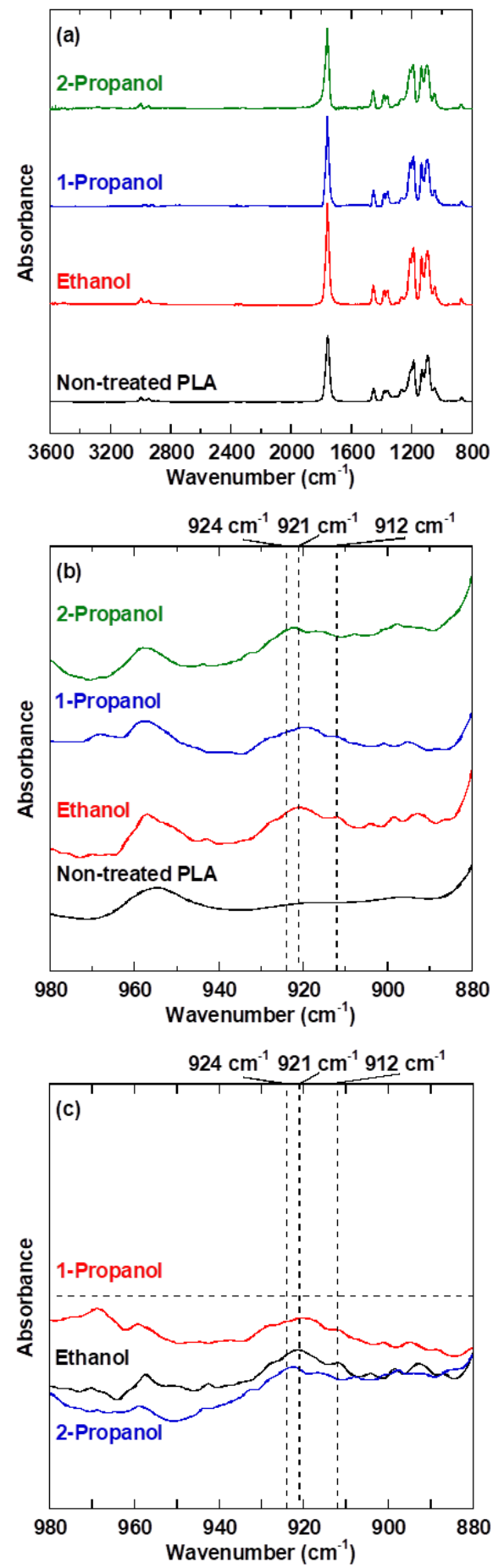

Figure 7 ATR-FTIR spectra of PLA membranes before [28] and after sorption measurements in ethanol, 1-propanol, and 2-propanol vapors (a) from $3600 \mathrm{~cm}^{-1}$ to $800 \mathrm{~cm}^{-1}$ and (b) from $980 \mathrm{~cm}^{-1}$ to $880 \mathrm{~cm}^{-}$ 1 and (c) difference spectra of PLA membranes before and after sorption measurement used in ethanol, 1-propanol and 2-propanol vapor from $980 \mathrm{~cm}^{-1}$ to $880 \mathrm{~cm}^{-1}$ were dispersed in POM images. The assumption was that crystallization occurred due to alcohol vapor sorption. In a past study, ethanol vapor permeation measurement was performed at $35^{\circ} \mathrm{C}$, and POM image of the PLA film after ethanol vapor permeation measurement was the almost same as that after ethanol vapor sorption in this study [38]. Therefore, the POM image of the PLA film after sorption was consistent. Meanwhile, the thermally- and solvent-induced crystallized PLA films became cloudy. As shown in the POM images, the domain of color change was uniformly dispersed. On the basis of the results mentioned above, the mechanisms underlying vapor-, thermally-, and solvent-induced crystallization were different.

Table 2 shows the film density and the contact angle of the membrane before and after the measurement of alcohol vapor and water vapor sorption, and after impregnation in alcohol and water in liquid state. The film densities after the sorption of alcohol vapor decreased and the contact angle increased compared with before sorption. These results may be due to the change in crystal structure on the film surface due to alcohol vapor sorption. In addition, the film densities after vapor sorption were lower than those after impregnation. These results can be attributed to the different crystallization and contraction processes of the membrane and to the swelling of the membrane due to the dissolution of alcohol and water in vapor and liquid states in the membrane. In addition, the cohesiveness of molecules during dissolution in liquid and vapor states were different, and the vapor state formed clusters with many molecules.

Figure 9 (a) shows the DSC curves of the PLA membrane before and after the measurement of ethanol, 1-propanol, 
Sorption components

Photographs

POM

$\times 1,000$

Non-treated PLA

Ethanol

1-Propanol

2-Propanol

Water

Thermally induced crystallization $\left(150^{\circ} \mathrm{C}, 48 \mathrm{~h}\right.$ annealing $)$

\section{Solvent induced crystallization (Ethanol liquid $24 \mathrm{~h}, 25^{\circ} \mathrm{C}$ )}
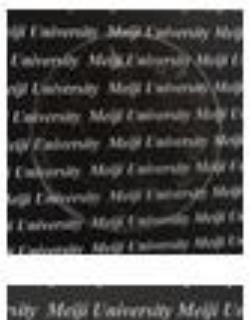

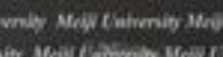

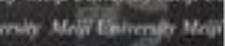

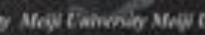

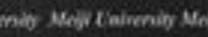

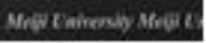

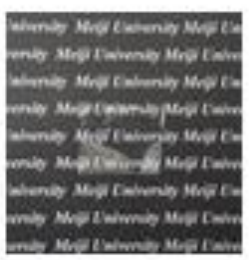

$10 \operatorname{\mu in}$
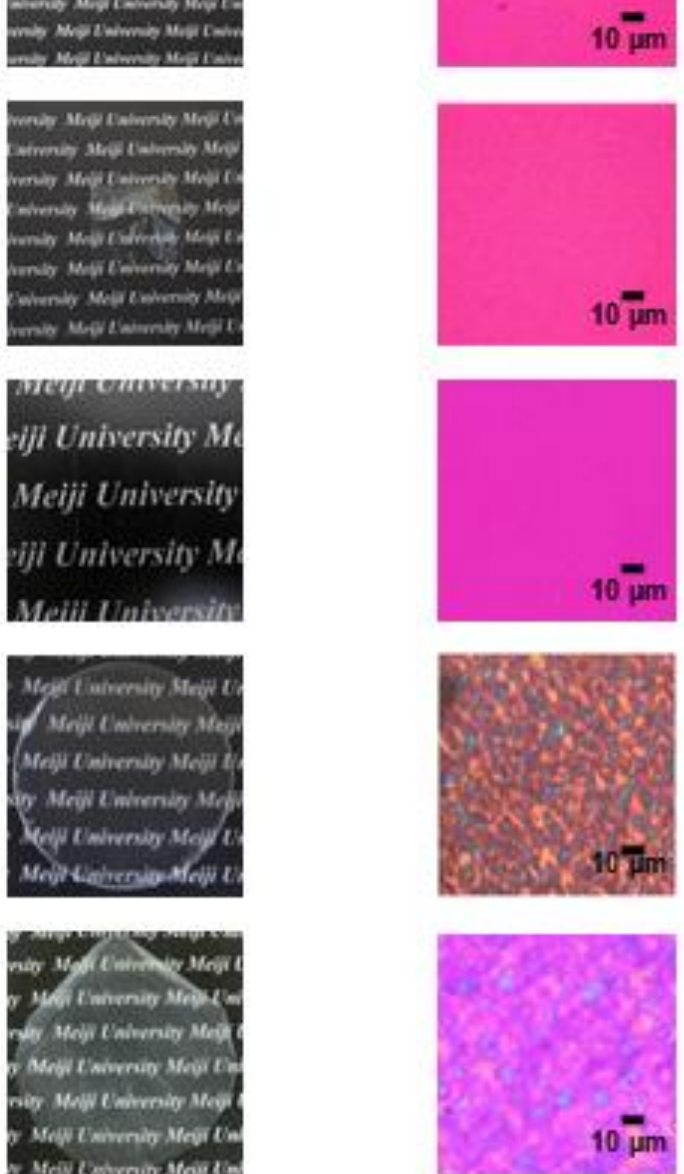

Figure 8 Photographs and POM images of PLA membranes before [28] and after sorption measurement in ethanol, 1-propanol, 2-propanol, and water [12] vapors, as well as thermally-[28] and solvent-[13] induced crystalline 
Table 2 Physical properties of PLA membranes before and after sorption measurement used in ethanol, 1-propanol, 2-propanol and water vapour

\begin{tabular}{cccc}
\hline $\begin{array}{c}\text { Vapor sorption } \\
\text { components }\end{array}$ & $\begin{array}{c}\text { Membrane density } \\
\left(\mathbf{g} / \mathbf{c m}^{\mathbf{3}}\right)\end{array}$ & $\begin{array}{c}\text { Membrane density } \\
\left(\mathbf{g} / \mathbf{c m}^{\mathbf{3}}\right) \\
(\mathbf{s o l v e n t})\end{array}$ & $\begin{array}{c}\text { Contact angle } \\
(\mathbf{d e g r e e})\end{array}$ \\
\hline Non-treated PLA & $1.257 \pm 0.001^{(\mathrm{a})}$ & $1.257 \pm 0.001^{(\mathrm{a})}$ & $69.5 \pm 1.2^{(\mathrm{b})}$ \\
Ethanol & $1.251 \pm 0.004$ & $1.252 \pm 0.001^{(\mathrm{c})}$ & $72.7 \pm 0.8$ \\
1-Propanol & $1.248 \pm 0.004$ & $1.252 \pm 0.002^{\text {(c) }}$ & $79.2 \pm 0.5$ \\
2-Propanol & $1.244 \pm 0.003$ & $1.254 \pm 0.002^{\text {(c) }}$ & $82.0 \pm 0.9$ \\
Water & - & $1.256 \pm 0.002^{\text {(c) }}$ & - \\
\hline
\end{tabular}

(a) Data from Reference [28]

(b) Data from Reference [38]

(c) Data from Reference [13]

2-propanol and water vapor sorption. The vertical axis indicates heat quantity, and the horizontal axis indicates temperature. An endothermic peak showing a glass transition at approximately $60 \quad{ }^{\circ} \mathrm{C}$ and an endothermic peak showing melting at approximately $150{ }^{\circ} \mathrm{C}$ were observed. The peak showing the glass transition of the PLA film before and after the sorption of water vapor appeared largely, whereas after alcohol sorption and peak appearance in the PLA film melting was observed. Thus, the crystal structure formed after vapor sorption.

Figure 9 (b) shows the DSC curve after ethanol, 1-propanol, and 2propanol vapor sorption at $110-170{ }^{\circ} \mathrm{C}$ near the melting peak. The peaks started to rise at approximately $120^{\circ} \mathrm{C}$ for all three types. Two of the peaks were included in one peak. Hence, all PLA membranes after alcohol vapor sorption were assumed to have two or more different crystal structures.

Table 3 shows the thermal properties and degree of crystallization before and after measurement of alcohol and water vapor sorption and after impregnation into alcohol and water. Table 3 shows that the sorption of alcohol and water vapors increased $X_{C-D S C}$ of the membrane. In addition, no significant difference was observed in $X_{C-D S C}$ after impregnation and sorption. Meanwhile, ethanol showed lower $T_{g}$ value than 1-propanol and 2-propanol, and ethanol showed higher $T_{c}$ value than 1-propanol and 2-propanol. Crystallization was assumed to have occurred due to sorption and dissolution of alcohol, thereby forming crystals. In addition, given that the final $X_{C-D S C}$ in liquid and vapor states showed the same value, the ratio of the crystal structure was assumed to be the same. Meanwhile, few spherulites were observed in the POM images of the PLA film after alcohol vapor sorption as shown in Figure 8. This result was assumed to be due to a large number of small spherulites, rather than some large spherulites, as the vapor was dispersed into crystalline nucleus. In addition, ethanol exhibited higher $T_{c}$ and lower $T_{g}$ than 1-propanol and 2propanol, indicating that crystal structure of the PLA membrane after ethanol vapor sorption was more thermally stable compared with those after 1-propanol and 2-propanol vapor sorption.

Figure 10 shows the mechanisms of solvent- and vapor-induced crystallization. In solvent-induced crystallization, the proportion of the crystalline region increased with a growth in the amount of crystal nuclei. Meanwhile, in vapor-induced crystallization, the size of the crystal nucleus did not change, but the amount of crystal nuclei increased because 

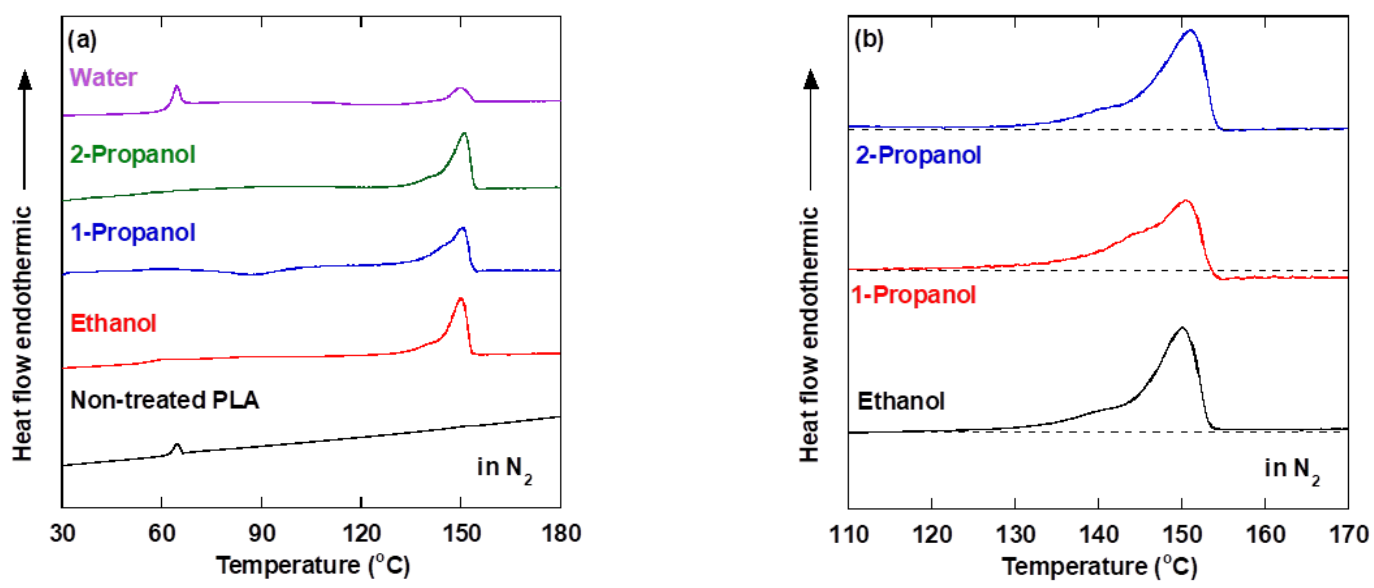

Figure 9 DSC thermograms of the first heating scan of PLA membranes (a) before [28] and after sorption measurement in ethanol, 1-propanol, 2-propanol and water vapor between $30{ }^{\circ} \mathrm{C}$ and $180{ }^{\circ} \mathrm{C}$, (b) after sorption measurement used in ethanol, 1-propanol, and 2-propanol between $110{ }^{\circ} \mathrm{C}$ and $170{ }^{\circ} \mathrm{C}$

Table 3 Thermal properties of PLA membranes before and after sorption measurement used in ethanol, 1-propanol, 2-propanol and water vapor

\begin{tabular}{|c|c|c|c|c|c|c|c|}
\hline $\begin{array}{c}\text { Vapor } \\
\text { sorption } \\
\text { components }\end{array}$ & $\begin{array}{c}T_{g} \\
\left({ }^{\circ} \mathbf{C}\right)\end{array}$ & $\begin{array}{c}T_{c} \\
\left({ }^{\circ} \mathbf{C}\right)\end{array}$ & $\begin{array}{c}\boldsymbol{T}_{\boldsymbol{m}} \\
\left({ }^{\circ} \mathbf{C}\right)\end{array}$ & $\begin{array}{l}\Delta \boldsymbol{H}_{c} \\
(\mathbf{J} / \mathbf{g})\end{array}$ & $\begin{array}{l}\Delta \boldsymbol{H}_{m} \\
(\mathbf{J} / \mathbf{g})\end{array}$ & $\begin{array}{c}X_{C} \\
(\%)\end{array}$ & $\begin{array}{c}X_{C}(\mathbf{b}) \\
(\%) \\
\text { (Induced } \\
- \\
\text { crystalliz } \\
\text { ation) } \\
\end{array}$ \\
\hline $\begin{array}{c}\text { Non-treated } \\
\text { PLA }^{(a)}\end{array}$ & $\begin{array}{c}58.1 \pm \\
0.1\end{array}$ & N/A & N/A & N/A & N/A & 0.0 & - \\
\hline Ethanol & $\begin{array}{c}55.2 \pm \\
0.1\end{array}$ & $\begin{array}{c}112.4 \pm \\
9.4\end{array}$ & $\begin{array}{c}150.2 \pm \\
0.0\end{array}$ & $\begin{array}{c}-3.4 \pm \\
0.1\end{array}$ & $\begin{array}{c}22.1 \pm \\
0.1\end{array}$ & $\begin{array}{c}20.1 \pm \\
0.1\end{array}$ & $25.1 \pm 1.5$ \\
\hline 1-Propanol & $\begin{array}{c}65.8 \pm \\
2.4\end{array}$ & $\begin{array}{c}97.8 \pm \\
5.5\end{array}$ & $\begin{array}{c}150.4 \pm \\
0.3\end{array}$ & $\begin{array}{c}-3.0 \pm \\
1.6\end{array}$ & $\begin{array}{c}28.0 \pm \\
3.6\end{array}$ & $\begin{array}{c}27.0 \pm \\
2.1\end{array}$ & $26.0 \pm 2.0$ \\
\hline 2-Propanol & $\begin{array}{c}62.1 \pm \\
0.5\end{array}$ & $\begin{array}{c}97.6 \pm \\
0.6\end{array}$ & $\begin{array}{c}150.7 \pm \\
0.5\end{array}$ & $\begin{array}{c}1.9 \pm \\
0.8\end{array}$ & $\begin{array}{c}24.0 \pm \\
1.6\end{array}$ & $\begin{array}{c}27.9 \pm \\
2.6\end{array}$ & $25.7 \pm 1.5$ \\
\hline Water & $\begin{array}{c}59.8 \pm \\
0.2\end{array}$ & $\begin{array}{c}125.8 \pm \\
0.4\end{array}$ & $\begin{array}{c}149.3 \pm \\
0.3\end{array}$ & $\begin{array}{c}-3.0 \pm \\
0.8\end{array}$ & $\begin{array}{c}3.5 \pm \\
0.9\end{array}$ & $\begin{array}{c}0.63 \pm \\
0.3\end{array}$ & $1.4 \pm 0.1$ \\
\hline
\end{tabular}

(a) Data from Reference [28].

(b) Data from Reference [13].

vapor was dispersed entire film. Therefore, the proportion of crystal region increased.

Figure 11 shows the UV-vis measurement results of the PLA film before and after the sorption of alcohol and water vapors. The vertical axis indicates transmittance, and the horizontal axis indicates wavelength. The final permeability of the PLA membrane after sorption of alcohol and water vapors decreased as compared with that before this process. Alcohol vapor also decreased in permeability compared with water vapor. This result may be due to the influence of permeability because the crystal structure was formed by sorption of water and alcohol vapors and the PLA films turned cloudy. Given that water 


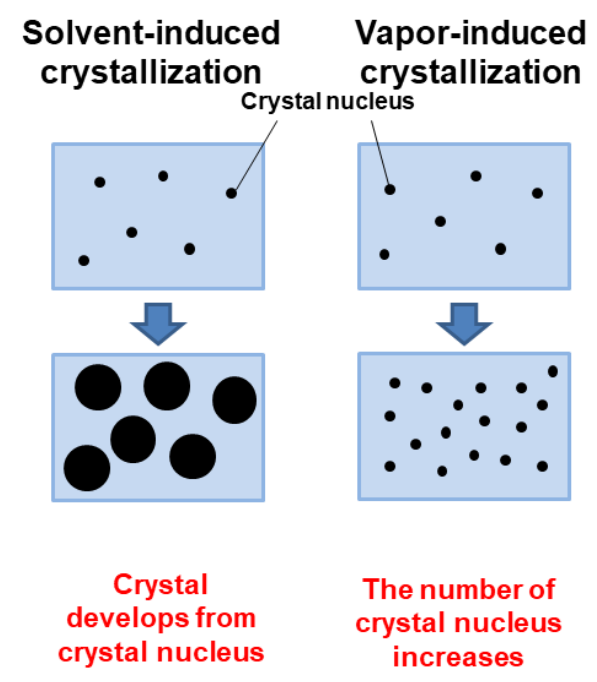

Figure 10 The image of difference in solvent- and vapor-induced crystallization

vapor is hardly crystallized, the permeability did not decrease much.

Figure 12 shows WAXD measurement results of the PLA membrane before and after alcohol vapor sorption. For comparison, water vapor and solvent impregnated data previously obtained are also plotted [12, 13]. The vertical axis represents intensity and the horizontal axis represents diffraction angle $2 \theta$. The peak of the crystal region was calculated by performing waveform separation by Gaussian function. Hellos were observed in the WAXD pattern before sorption and after water vapor sorption, whereas sharp peaks were observed in the WAXD pattern after alcohol vapor sorption at $16.8^{\circ}$ and $19^{\circ}$. WAXD measurement and DSC results showed that, the crystal structure was formed by alcohol vapor sorption. The pattern of ethanol vapor sorption showed deviating peaks slightly showing crystals compared with those of 1-propanol and 2-propanol. The peak position deviated when impregnated with a solvent. Thus, the crystals of a similar degree of $X_{C-D S C}$ were formed by alcohol vapor sorption from peak

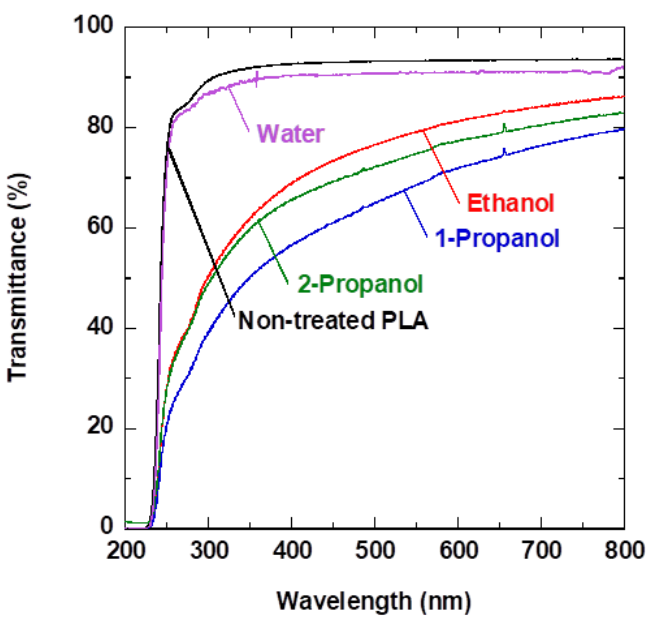

Figure 11 UV-vis spectra of PLA membranes before [28] and after sorption measurements in ethanol, 1-propanol, 2propanol, and water vapors

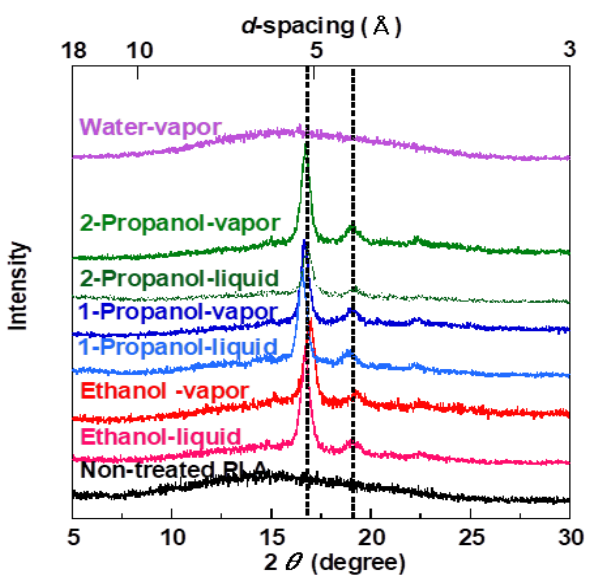

Figure 12 WAXD patterns of PLA membranes before [28] and after sorption measurement used in ethanol, 1-propanol, 2-propanol, and water [12] vapors, and solvent-induced PLA membranes [13]

intensity. Presumably, ethanol formed a different crystal structure from 1propanol and 2-propanol. In addition, crystallization by vapor was caused by a mechanism different from solventinduced crystallization, because the peak position when impregnated with solvent was different from the peak position after vapor sorption. Meanwhile, the sorption of water vapor did not form a crystal structure that appeared in the WAXD pattern. 
Table 4 WAXD properties of PLA membranes after sorption measurement used in ehanol, 1propanol, 2-propanol, and water vapour

\begin{tabular}{cccc}
\hline \multirow{2}{*}{$\begin{array}{c}\text { Vapor sorption } \\
\text { components }\end{array}$} & \multicolumn{2}{c}{$\begin{array}{c}\text { Diffraction angle } \\
(\boldsymbol{\theta})\end{array}$} & $\begin{array}{c}\boldsymbol{d} \text {-spacing } \\
(\boldsymbol{\AA})\end{array}$ \\
\cline { 2 - 3 } & $\mathbf{1 s t}$ & 2nd & \\
\hline Non-treated PLA ${ }^{(\mathrm{a})}$ & $\mathrm{N} / \mathrm{A}$ & $\mathrm{N} / \mathrm{A}$ & $5.82 \pm 0.00$ \\
Ethanol & $16.8 \pm 0.01$ & $19.2 \pm 0.01$ & $5.93 \pm 0.05$ \\
1-Propanol & $16.6 \pm 0.01$ & $19.1 \pm 0.02$ & $5.97 \pm 0.02$ \\
2-Propanol & $16.7 \pm 0.01$ & $19.0 \pm 0.01$ & $5.96 \pm 0.02$ \\
Water $^{(\mathrm{b})}$ & $\mathrm{N} / \mathrm{A}$ & $\mathrm{N} / \mathrm{A}$ & - \\
\hline
\end{tabular}

(a) Data from Reference [28].

(b) Data from Reference [12].

Table 4 shows the diffraction angle of the peak showing sharp crystals calculated from the WAXD pattern and the polymer chain gap in the amorphous region. Water vapor data previously conducted are also plotted as a comparison. No sharp peaks were observed on the PLA membrane before and after water vapor sorption. In addition, the PLA films after alcohol sorption revealed sharp peaks showing the crystal structure at approximately $16.8^{\circ}$ and $19^{\circ}$. The value of the polymer chain gap in the amorphous region slightly increased after than before alcohol vapor sorption. Thus, swelling plasticization of the PLA membrane occurred due to alcohol vapor sorption. Here, the $\alpha$-type crystal structure of PLA showed peaks at $14.8^{\circ}, 16.8^{\circ}$, $19.1^{\circ}$, and $22.5^{\circ}$; the $\beta$-type crystal structure showed peaks at $16.5^{\circ}, 18.8^{\circ}$, $24.5^{\circ}$, and $28.8^{\circ}$; and the $\alpha^{\prime}$-type crystal structure showed peaks at $14.8^{\circ}, 16.5^{\circ}$, $18.8^{\circ}$, and $24.5^{\circ}[16-26]$. Studies have yet to report that the $\gamma$-type crystal structure shows a peak at any diffraction angle. In the WAXD pattern, no peak was observed at approximately $28.8^{\circ}$, indicating the presence of $\beta$-type crystal structure. Meanwhile, the peak was observed at approximately $14.8^{\circ}$, indicating the present of $\alpha$ - and $\alpha^{\prime}$-type crystal structures. Therefore, $\alpha-$ and $\alpha^{\prime}-$ type crystal structures were formed by alcohol vapor sorption. However, ATR-
FTIR spectra showed the structures of $\alpha$ - and $\beta$-type crystals. Therefore, in the WAXD pattern, three types of waveforms, that is, $\alpha, \beta$, and $\alpha^{\prime}$ separated in the diffraction angle ranging from $15^{\circ}$ to $18^{\circ}$ in the WAXD pattern.

Figure 13 (a), 14 (a), and 15 (a) show the results of the waveform separation of the WAXD pattern in the diffraction angle ranging from $15^{\circ}$ to $18^{\circ}$ after the sorption of ethanol, 1propanol and 2-propanol vapors. In the diffraction angle range from $15^{\circ}$ to $18^{\circ}$, the diffraction angles of the peaks showing $\beta$ - and $\alpha^{\prime}$-type crystal structures were the same indistinguishable and expressed as $\alpha^{\prime}$ or $\beta$. As a result of the waveform separation, the crystal structure obtained did not peak fit only with $\alpha$ and $\beta$ - or $\alpha^{\prime}$-type crystal structures. Thus, waveform separation was newly performed by combining peaks near the diffraction angle of $17^{\circ}$.

Figure 13 (b), 14 (b), and 15 (b) show the results of the WAXD pattern, in which waveform separation was performed with three peaks after the sorption of the three types of vapor. The crystal structure showing a peak the 

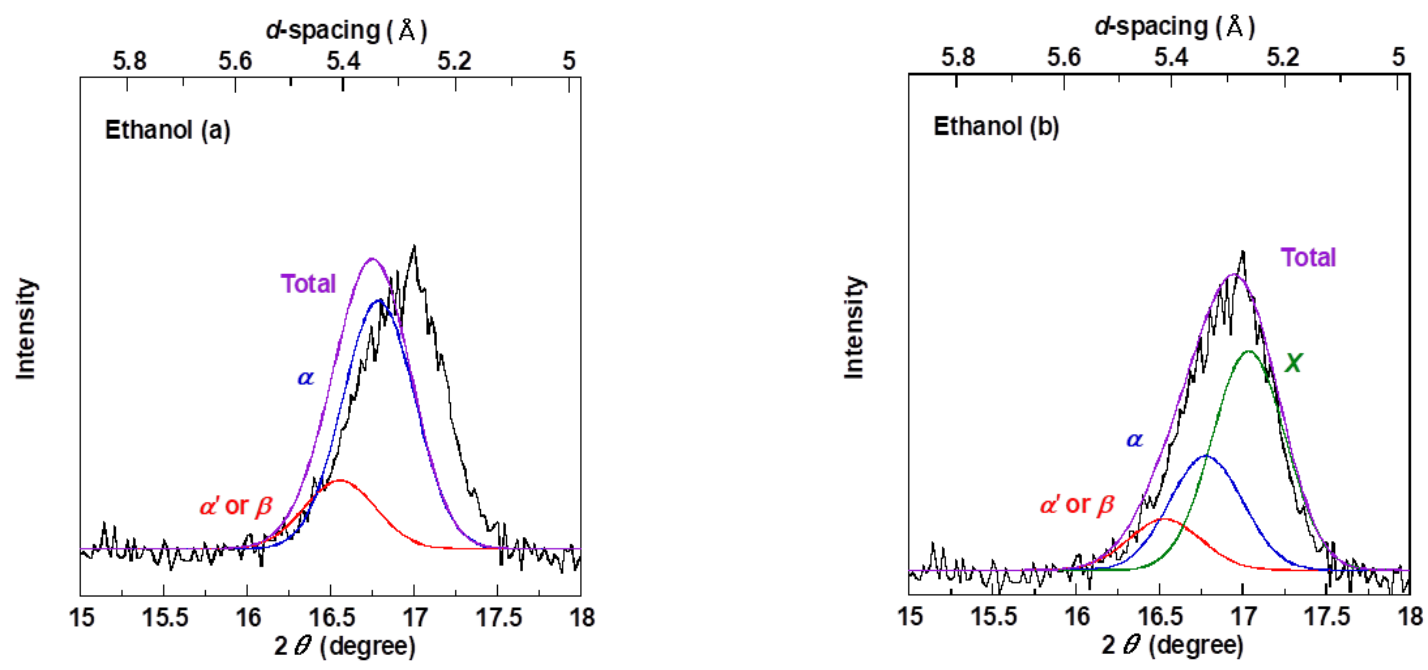

Figure 13 Waveform separation of Gaussian functions for (a) $\alpha, \alpha$, and $\beta$ crystal structure and (b) $\alpha, \alpha^{\prime}, \beta$, and X crystal structure by the WAXD patterns of PLA membrane after sorption measurement in ethanol
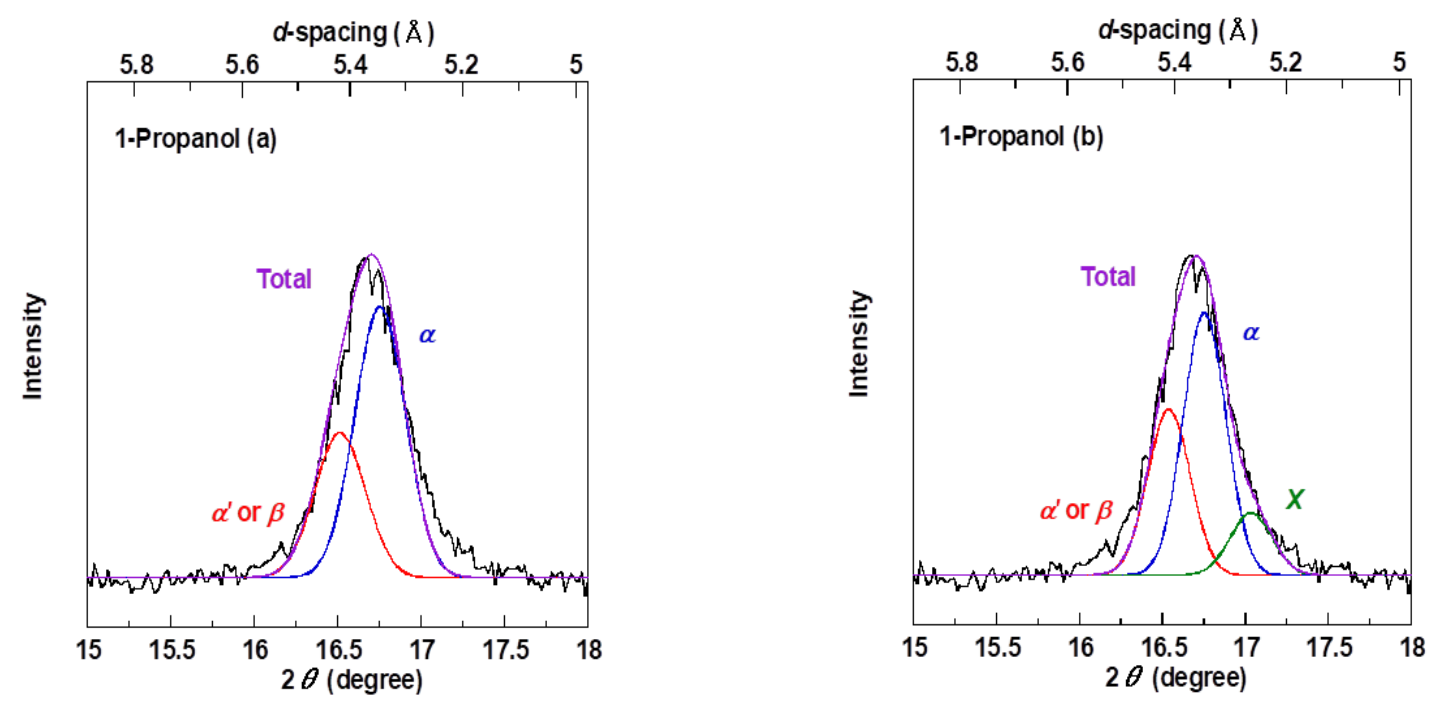

Figure 14 Waveform separation of Gaussian functions for (a) $\alpha, \alpha^{\prime}$, and $\beta$ crystal structure and (b) $\alpha, \alpha^{\prime}, \beta$, and X crystal structure by the WAXD patterns of PLA membrane after sorption measurement in 1-propanol

diffraction angle of approximately $17^{\circ}$ newly added this time did not correspond to any of the abovementioned $\alpha-, \beta-, \quad \alpha^{\prime}$-type crystals: therefore, this crystal structure was written as $\mathrm{X}$. The peak fitted in all WAXD patterns after performing waveform separation by newly combining peaks at approximately $17^{\circ}$. $\alpha-, \beta-, \alpha^{\prime}-$, and X-type crystal structures were formed in all PLA membranes after alcohol vapor sorption. However, $X$ crystal structure cannot be determined at present. The larger the diffraction angle was, the more thermally stable crystal structure was formed. Ethanol showed a sharp peak at a large diffraction angle compared with 1-propanol and 2-propanol, the crystal structure of the PLA membrane was more thermally stable after the sorption of ethanol vapor than after the sorption 

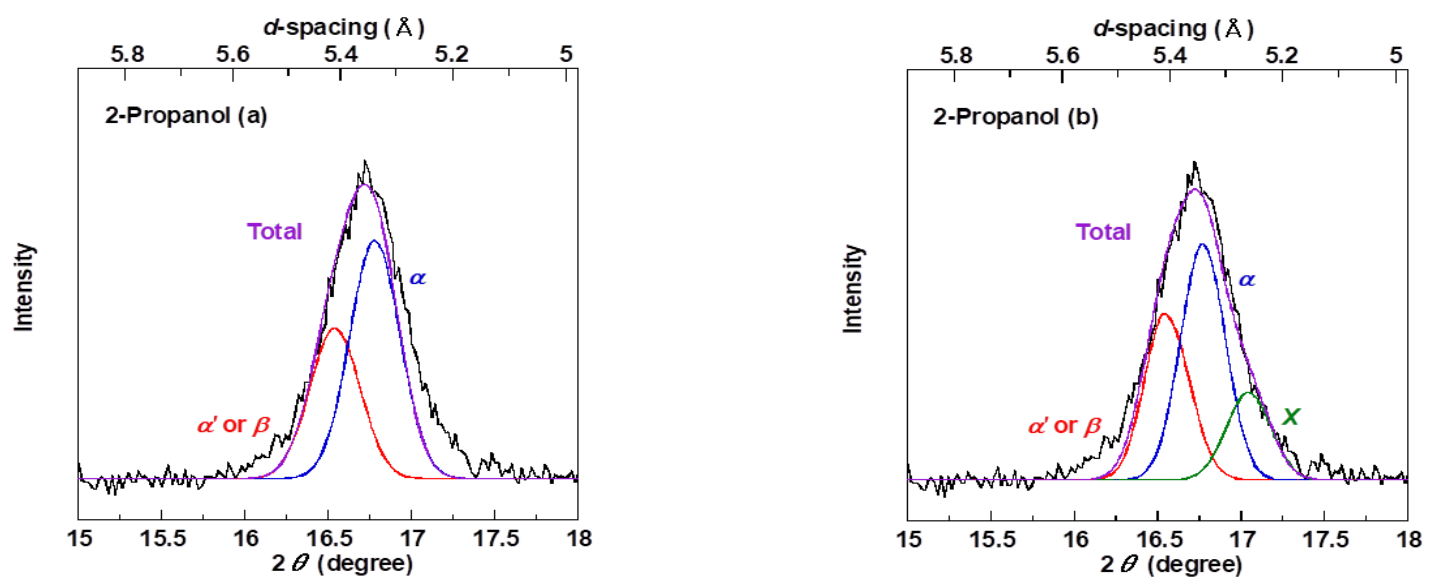

Figure 15 Waveform separation of Gaussian functions for (a) $\alpha, \alpha^{\prime}$, and $\beta$ crystal structure and (b) $\alpha, \alpha^{\prime}, \beta$, and X crystal structure by the WAXD patterns of PLA membrane after sorption measurement in 2-propanol

of 1-propanol and 2-propanol vapors. Considering that the same trend was observed from the DSC measurement results, the crystal structure formed by changing the number of carbons in the alcohol vapor was different, and shown to be positioned as an intermediate in the process of rearrangement of the PLA chains from amorphous to thermally stable $\alpha$-type crystallization.

\subsection{CONCLUSIONS}

In this study, organic vapor adsorption to PLA was measured to elucidate the influence of organic vapor used as a perfume ingredient on the PLA membrane. Sorption amount was increased as the molecular volume of vapor was decreased in the lowpressure region. The sorption amount of molecules with side chains was reduced compared with molecules without side chains. Meanwhile, in the high-pressure region, PLA films caused swelling and plasticization as the cluster size increased, and the increase rate of sorption further increased. Moreover, vapor sorption on the PLA membrane caused vapor-induced crystallization. Unlike solvent- and thermally-induced crystallization, vapor-induced crystallization was characterized by the following each single crystal nucleus was small even with the same degree of crystallinity, and the crystal nucleus was dispersed in the polymer chain. In addition, its crystal structure was positioned as an intermediate in the process of rearrangement of PLA chains from amorphous to $\alpha$-type crystallization. WAXD pattern analysis, a crystal structure that was not identified, was also formed.

\section{ACKNOWLEDGEMENT}

This research was partially supported by a Grant-in-aid for Scientific Research C (15K06493) from the Ministry of Education, Culture, Sports, Science and Technology, Japan, Japan Society of the Promotion of Science.

\section{REFERENCES}

[1] R. Jambeck Jenna, M. Perryman, R. Geyer, C. Wilcox, R. Siegler Theodore, A. Andrady, R. Narayan, and L. Law Kara. 2015. Marine Pollution. Plastic Waste Inputs from Land into the Ocean. Science. 347: 768-771. 
[2] H. S. Carson, S. L. Colbert, M. J. Kaylor, and K. J. McDermid. 2011. Small Plastic Debris Changes Water Movement and Heat Transfer through Beach Sediments. Mar. Pollut. Bull. 62: 1708-1713.

[3] E. Possatto Fernanda, L. Spach Henry, P. Cattani Andre, R. Lamour Marcelo, O. Santos Lilyane, M. A. Cordeiro Nathalie, and K. Broadhurst Matt. 2015. Marine Debris in a World Heritage Listed Brazilian Estuary. Mar. Pollut. Bull. 91: 548-553.

[4] A. Isobe, K. UchiyamaMatsumoto, K. Uchida, and T. Tokai. 2017. Microplastics in the Southern Ocean. Mar. Pollut. Bull. 114: 623-626.

[5] J. L. Lavers, S. Oppel, and A. L. Bond. 2016. Factors Influencing the Detection of Beach Plastic Debris. Mar. Environ. Res. 119: 245-251.

[6] G. A. Giles and D. R. Bain. 2000. Materials and Development of Plastics Packaging for the Consumer Market. England: Sheffield Academic Press. 16-45.

[7] S. M. Emadian, T. T. Onay, and B. Demirel. 2017. Biodegradation of Bioplastics in Natural Environments. Waste Manage. (Oxford, U. K.). 59: 526-536.

[8] R. Iida, T. Yonezu, Y. Shinkawa, and K. Nagai. 2016. Reversible Selectivity of Water/Organic Solvent Mixtures in Poly(lactic acid) Film. J. Appl. Polym. Sci. 133: 43822/43821-43822/43810.

[9] T. Komatsuka, A. Kusakabe, and K. Nagai. 2008. Characterization and Gas Transport Properties of Poly(Lactic Acid) Blend Membranes. Desalination. 234: 212-220.

[10] Y. Shinkawa, Y. Hayashi, S. Sato, and K. Nagai. 2015. Permeability of Ethanol Solution Through
Poly(Lactic Acid) Film. J. Appl. Polym. Sci. 132: 42031/4203142031/42039.

[11] Z. Javidi, S.F. Hosseini, and M. Rezaei. 2016. Development of Flexible Bactericidal Films Based on Poly(Lactic Acid) and Essential Oil and Its Effectiveness to Reduce Microbial Growth of Refrigerated Rainbow Trout. LWT--Food Sci. Technol. 72: 251-260.

[12] T. Saiga, S. Sato, and K. Nagai. 2015. Water Vapor Solubility of Poly(Lactic Acid) Films Modified the Surface by Vacuum Ultraviolet Irradiation. J. Appl. Polym. Sci. 132: 42200/4220142200/42208.

[13] S. Sato, D. Gondo, T. Wada, S. Kanehashi, and K. Nagai. 2013. Effects of Various Liquid Organic Solvents on SolventInduced Crystallization of Amorphous Poly(Lactic Acid) Film. J. Appl. Polym. Sci. 129: 1607-1617.

[14] S. Sato, T. Wada, R. Ido, Y. Murakoshi, S. Kanehashi, and K. Nagai. 2014. Dependence of Alcohol Vapor-induced Crystallization on Gas and Vapor Permeabilities of Poly(Lactic Acid) Films. J. Appl. Polym. Sci. 131: 40140/40141-40140/40149.

[15] A. Hauer. 2007. Sorption Theory for Thermal Energy Storage. NATO Sci. Ser. II. 234: 393-408.

[16] M. Yasuniwa, S. Tsubakihara, K. Iura, Y. Ono, Y. Dan, and K. Takahashi. 2006. Crystallization Behavior of Poly(L-lactic Acid). Polymer. 47: 7554-7563.

[17] J. Puiggali, Y. Ikada, H. Tsuji, L. Cartier, T. Okihara, and B. Lotz. 2000. The Frustrated Structure of Poly(L-lactide). Polymer. 41: 8921-8930.

[18] D. Sawai, K. Takahashi, A. Sasashige, T. Kanamoto, and S.- 
H. Hyon. 2003. Preparation of Oriented $\beta$-Form Poly(L-lactic acid) by Solid-State Coextrusion: Effect of Extrusion Variables. Macromolecules. 36: 3601-3605.

[19] S. Sasaki and T. Asakura. 2003. Helix Distortion and Crystal Structure of the $\alpha$-Form of Poly(L-lactide). Macromolecules. 36: 8385-8390.

[20] J. Zhang, Y. Duan, H. Sato, H. Tsuji, I. Noda, S. Yan, and Y. Ozaki. 2005. Crystal Modifications and Thermal Behavior of Poly(L-lactic acid) Revealed by Infrared Spectroscopy. Macromolecules. 38: 8012-8021.

[21] D. Sawai, T. Yokoyama, T. Kanamoto, M. Sungil, S.-H. Hyon, and L.P. Myasnikova. 2006. Crystal Transformation and Development of Tensile Properties Upon Drawing of Poly(L-lactic acid) by Solid-state Coextrusion: Effects of Molecular Weight. Macromol. Symp. 242: 93-103.

[22] Y. Wang, S. S. Funari, and J. F. Mano. 2006. Influence of Semicrystalline Morphology on the Glass Transition of Poly(Llactic acid). Macromol. Chem. Phys. 207: 1262-1271.

[23] P. Pan, B. Zhu, W. Kai, T. Dong, and Y. Inoue. 2008. Effect of Crystallization Temperature on Crystal Modifications and Crystallization Kinetics of Poly(L-lactide). J. Appl. Polym. Sci. 107: 54-62.

[24] P. Pan, B. Zhu, W. Kai, T. Dong, and Y. Inoue. 2008. Polymorphic Transition in Disordered Poly(Llactide) Crystals Induced by Annealing at Elevated Temperatures. Macromolecules. 41: 4296-4304.

[25] J. Zhang, K. Tashiro, H. Tsuji, and A. J. Domb. 2008. Disorder-
to-Order Phase Transition and Multiple Melting Behavior of Poly(L-lactide) Investigated by Simultaneous Measurements of WAXD and DSC. Macromolecules. 41: 1352-1357.

[26] K. Wasanasuk, K. Tashiro, M. Hanesaka, T. Ohhara, K. Kurihara, R. Kuroki, T. Tamada, T. Ozeki, and T. Kanamoto. 2011. Crystal Structure Analysis of Poly(l-lactic Acid) $\alpha$ Form on the basis of the 2-Dimensional WideAngle Synchrotron X-ray and Neutron Diffraction Measurements. Macromolecules. 44: 6441-6452.

[27] K. Momma and F. Izumi. 2008. VESTA: A Three-dimensional Visualization System for Electronic and Structural Analysis. J. Appl. Cryst. 41: 653658.

[28] H. Sawada, Y. Takahashi, S. Miyata, S. Kanehashi, S. Sato, and K. Nagai. 2010. Gas Transport Properties and Crystalline Structures of Poly(Lactic Acid) Membranes. Trans. Mater. Res. Soc. Jpn. 35: 241-246.

[29] K. Nagai, A. Sugawara, S. Kazama, and B. D. Freeman. 2004. Effects of Physical Aging on Solubility, Diffusivity, and Permeability of Propane and NButane in Poly(4-methyl-2pentyne). J. Polym. Sci., Part B Polym. Phys. 42: 2407-2418.

[30] B. E. Poling. 2001. The Properties of Gases and Liquids. New York: McGraw-Hill. A.6A.49.

[31] J. L. Lundberg. 1972. Molecular Clustering and Segregation in Sorption Systems. Pure Appl. Chem. 31: 261-281.

[32] B. H. Zimm. 1953. Simplified Relation between Thermodynamics and Molecular 
Distribution Functions for a Mixture. J. Chem. Phys. 21: 934935.

[33] Y. Kong and J. N. Hay. 2002. The Measurement of the Crystallinity of Polymers by DSC. Polymer. 43: 3873-3878.

[34] Y. Kong and J. N. Hay. 2003. The Enthalpy of Fusion and Degree of Crystallinity of Polymers as Measured by DSC. Eur. Polym. J. 39: 1721-1727.

[35] E. W. Fischer, H. J. Sterzel, and G. Wegner. 1973. Investigation of the Structure of Solution Grown Crystals of Lactide Copolymers By Means of Chemicals Reactions. Kolloid-Z. Z. Polym. 251: 980-990.

[36] C. C. McDowell, B. D. Freeman, G. W. McNeely, M. I. Haider, and A. J. Hill. 1998. Synthesis,
Physical Characterization, and Acetone Sorption Kinetics in Random Copolymers of Poly(ethylene terephthalate) and Poly(ethylene 2,6-naphthalate). $J$. Polym. Sci., Part B Polym. Phys. 36: 2981-3000.

[37] C. M. Hansen. 2007. Hansen Solubility Parameters A User's Handbook. Boca Raton: CRC Press. 411-457.

[38] S. Sato, M. Ono, J. Yamauchi, S. Kanehashi, H. Ito, S. Matsumoto, Y. Iwai, H. Matsumoto, and K. Nagai. 2012. Effects of Irradiation with Vacuum Ultraviolet Xenon Excimer Lamp at $172 \mathrm{Nm}$ on Water Vapor Transport through Poly(lactic acid) Membranes. Desalination. 287: 290-300. 